\title{
Depressing effect of fine hydrophilic particles on magnesite reverse flotation
}

\author{
J. Yao ${ }^{1}$, W. Yin ${ }^{2, *}$, E. Gong ${ }^{3}$
}

${ }^{1}$ College of Resources and Civil Engineering, Northeastern University, Liaoning, Shenyang 110819, China. Email: yaojin@mail.neu.edu.cn

2,* College of Resources and Civil Engineering, Northeastern University, Liaoning, Shenyang 110819, China. Corresponding author, email:1402541@qqq.com

${ }^{3}$ College of Resources and Civil Engineering, Northeastern University, Liaoning, Shenyang 110819, China. Email: gongep@mail.neu.edu.cn

\begin{abstract}
The influence of fine particles on the flotation separation of minerals is becoming increasingly important as new, fine grained deposits are exploited. Fine particles float poorly and less selectively under normal flotation conditions, having detrimental effects on recovery of other minerals. The reasons of this interacting effect are complex, which may be entrainment, $\mathrm{pH}$ variation, dissolved ions from mineral surfaces, aggregation/dispersion and coating behavior of particles or even the competitive adsorption effect. In this study, the influence of fine magnesite and dolomite on the flotation of quartz was investigated. It was found that at $\mathrm{pH}=9.2 \sim 9.5$ and with DDA dosage of $8.6 \times 10^{-4}$, the recovery of coarse $(-100+65 \mu \mathrm{m})$ quartz was reduced dramatically from $96.66 \%$ to $37.15 \%$ when the content of quartz was $5 \%$ in the flotation with fine $(-5 \mu \mathrm{m})$ magnesite, and when the content of fine dolomite was increased from $2.5 \%$ to $20 \%$, the recovery of coarse quartz was reduced from $91.20 \%$ to $75.08 \%$. To examine the reasons, zeta potential, zero point of charge and contact angles of magnesite, dolomite and quartz were measured in the absence and presence of dodecylamine (DDA). The interaction energies between particles were then calculated. Results showed that the aggregation behavior of mineral particles was likely to be the reason. Interaction energy calculated based on Extended-DLVO (Derjaguin-Landau-Verwey-Overbeek) theory predicted that in DDA surfactant solution, the interaction forces between magnesite and quartz, dolomite and quartz were attractive, between dolomite and magnesite was repulsive. The experimental results are in excellent agreement with the theoretically predicted results. The aggregation caused by interacting behavior explains the depressing effect of fine hydrophilic particles on magnesite reverse flotation.
\end{abstract}

Keywords: flotation, Extended-DLVO, fine particles, interfacial interaction

\section{Nomenclature}

A Hamaker constant (J)

$A_{132}$ Effective hamaker constant of materials 1, 2 in medium $3(\mathrm{~J})$

$c \quad$ Concentration $\left(\mathrm{mol} \mathrm{m}^{-3}\right)$

$e \quad$ Electronic charge, $1.602 \times 10^{-19} \mathrm{C}$

$H \quad$ Minimum separation distance between two spheres (m)

$L \quad$ Liquid materials

$N_{\mathrm{A}} \quad$ Avogadro number, $6.023 \times 10^{23} \mathrm{~mol}^{-1}$

$k \quad$ Boltzmann's constant, $1.3806 \times 10^{-23} \mathrm{~J} \mathrm{~K}^{-1}$

$P_{0} \quad$ Parameter in Eqs. (7), when calculating the retardation coefficient

$R_{1}, R_{2} \quad$ Radius of particles 1 and $2(\mathrm{~m})$

$S \quad$ Solid materials

$T \quad$ Temperature (K)

$V_{W} \quad$ Interaction energy due to Van der Waals forces $(\mathrm{J})$

$V_{\mathrm{E}} \quad$ Interaction energy due to electrical double layer effects (J)

$V_{\mathrm{H}} \quad$ Interaction energy due to hydration/hydrophobic effects (J)

$V_{\mathrm{H}}{ }^{0} \quad$ The acid-base free energy per unit area $(\mathrm{J})$

$V_{\mathrm{TD}} \quad$ Total interaction energy by DLVO theory $(\mathrm{J})$

$V_{\text {TED }} \quad$ Total interaction energy by EDLVO theory $(\mathrm{J})$

$z \quad$ Valence

$\gamma_{i}^{\mathrm{LW}} \quad$ The parameter of apolar (Lifshitz-van der Waals) component of surface tension of 


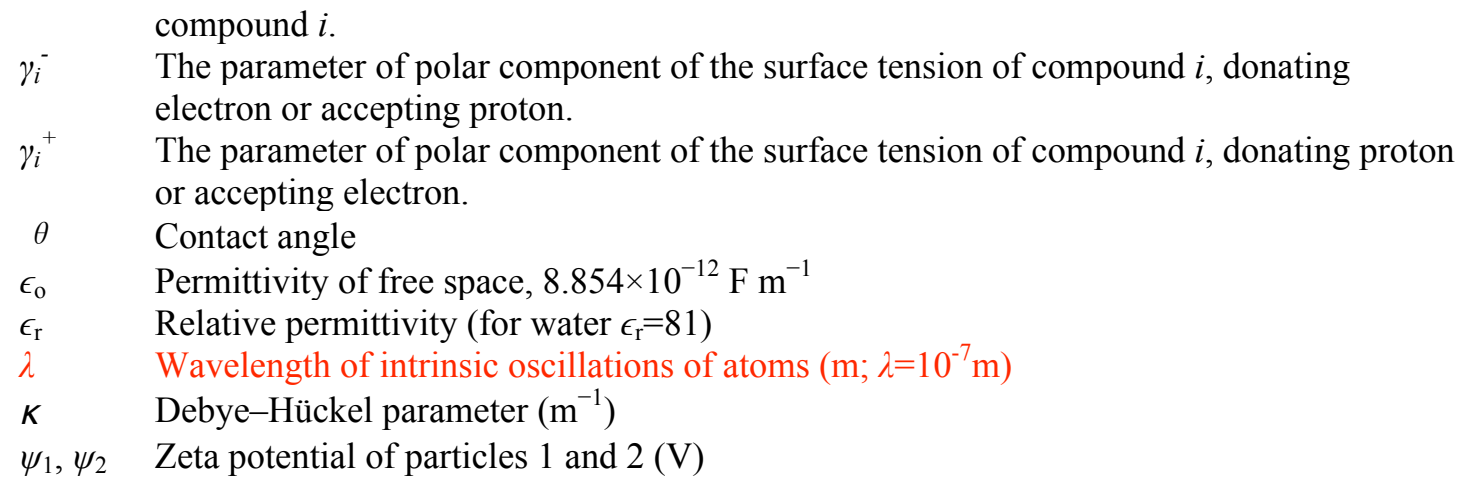

\section{Introduction}

Magnesite is the most important raw material utilized in the refractories industry for the manufacturing of basic refractories, having a high corrosion resistance in the presence of basic slags, dusts and fumes (Karaoglu et al., 2016). The reserves of magnesite in China is 13 billion tons, taking the first place in the world. In the recent years, as the high grade magnesite were being used up, many research have been done to process the low grade ores. Froth flotation was used for magnesite mineral processing as early as in 1930s by Doerner and Dwigh (Chen and Tao, 2004). Their work showed that it was quite easy to separate silicate minerals from magnesite in neutral pulps using alkyl sulfonate as collector and caustic soda as depressant. The surface properties of magnesite mineral, silicate, quartz and various iron minerals are known to be different. They can be readily separated by flotation. A. N. Santana and A. E. C. Peres (2001) have proposed cationic reverse magnesite flotation using a commercial mono ether amine as collector and corn starch as depressant. Anastassakis (1999) proposed an innovative method to separate magnesite fines from serpentine fines by magnetic carrier. Gence and Ozdag (1995) examined the adsorption mechanism of sodium oleate and amine in magnesite-serpentine flotation, and verified that $\mathrm{RCOO}^{-}$ion was chemically adsorbed on the surface of magnesite, and it was physically adsorbed on the surface of serpentine while $\mathrm{NH}^{3+}$ ion was physically adsorbed on the surfaces of both minerals. Many Researchers have also attempted to apply biological methods to beneficiate magnesite (Botero et al., 2008; Karaoglu et al., 2016).

However, the influence of fine particles on the flotation separation of minerals is becoming increasingly important as new, fine grained deposits are exploited. Fine particles float poorly and less selectively under normal flotation conditions, having detrimental effects on recovery of other minerals. During flotation process, selectivity problem arises between magnesite and associated gangue minerals. Ozkan (2002) have investigated the beneficiation of magnesite slimes with ultrasonic treatment in order to achieve flotation for $-38 \mu \mathrm{m}$ magnesite wastes effectively, and found that the simultaneously ultrasonic treatment and pre-treatment for magnesite slime had positive effect on the recovery values compared to the results of conventional flotation. In the research done by authors, an interesting phenomenon has been found that fine mineral particles had interactive effects on each other that could depress another mineral. The interactive effect between minerals was reported several times by researchers in the perspective of carrier flotation, shear flocculation or oil agglomeration etc.

Lange et al. (1997) have investigated the behavior of fine and coarse sphalerite in micro flotation and aggregation studies. This study utilizes On-line particle size distribution techniques for obtaining direct evidence of particle interactions within a conditioning pulp, and evidence of particle interactions has been observed using optical microscopy. It was found that fine particles exhibit poor flotation response, and in the presence of coarse particles at low $\mathrm{pH}$, a high percentage of fine particles were recovered indicating a fine-coarse particle aggregation ("piggy-backing") mechanism occurring. Flocculation induced by hydrophobic interaction between fine mineral particles plays a predominant role in many techniques of fine particle separation, such as shear flocculation, emulsion flotation, carrier flotation, spherical agglomeration, etc.

Duzyol (2011, 2010) and Ozkan (2014, 2010) have studied the role of wettability, hydrophobicity and surface tension on shear flocculation and oil agglomeration of magnesite and dolomite. The correlations of shear flocculation and oil agglomeration processes of magnesite and 
dolomite with their wettability parameters were investigated. Their work contributed to the development of separation of minerals with flocculation and agglomeration techniques by determining the $\gamma_{c}$ (critical surface tension) values.

The surface hydrophobicity of magnesite and dolomite minerals was investigated by Nermin Gence (2006) in the absence and presence of sodium oleate. The surface properties of minerals play a major role in determining their separation from each other in processes such as flotation. The interactive effects between minerals may be explainable by surface tension and interacting energy calculation. Lu and Song (1991) investigated the flocculation behavior of fine mineral particles rendered hydrophobic by the surfactant and the mechanism of hydrophobic flocculation. The results showed that changes in wettability of mineral surface significantly affects the stability of fine particle suspensions. However, the hydrophobization of particle surface is often accompanied by a distinct flocculation which may by no means be interpreted by DLVO (Derjaguin-Landau-Verwey-Overbeek) theory. The potential energy of hydrophobic interaction between mineral particles rendered hydrophobic by surfactant far exceeds that resulting from double layer or van der Waals interactions. The extended-DLVO theory considering hydrophobic and hydrophilic interactions may be able to explain the fine particles interactions in flotation process.

In the abovementioned research the positive interactive effect between mineral particles was utilized. However, the negative depressing effect has also influences on the flotation process and strongly decreased the efficiency of minerals processing. In this study, the negative interactive effect between mineral particles and its mechanism has been discussed. The micro-flotation tests of single mineral and artificial mixtures were conducted and analyzed with the theoretical predictions by Extended-DLVO theory base on Van Oss's interaction energy calculation. Electrokinetic potential, zero point of charge and contact angles of pure magnesite, dolomite and quartz with and without surfactant Dodecylamine (DDA) were determined, in order to examine the particles interaction energy and its mechanisms in magnesite-dolomite-quartz cationic reverse flotation.

\section{Experimental}

\subsection{Samples and reagents}

The pure magnesite $\left(\mathrm{MgCO}_{3}\right)$, dolomite $\left(\mathrm{CaMg}\left(\mathrm{CO}_{3}\right)_{2}\right)$ and quartz $\left(\mathrm{SiO}_{2}\right)$ ore samples were obtained from Haicheng of Liaoning Province, China. The high grade lump magnesite, dolomite and quartz crystal were carefully selected to avoid cracks and inclusions for the contact angle measurements. The ore samples were crushed, handpicked and then dry-ground with a porcelain ball mill and dry-sieved to obtain the size fractions $-100+65 \mu \mathrm{m}$ for the single mineral-flotation tests. The $-5 \mu \mathrm{m}$ fraction of magnesite and dolomite was obtained by elutriation method and used for artificial mineral flotation tests and zeta-potential measurements. The elutriation method is a usual method used to measure the size of fine particles, which is based on the following equation.

$$
d=\sqrt{\frac{h}{545\left(\rho_{s}-1000\right) t}}
$$

In equation (1): $d$ is the diamater of particles $(\mathrm{m}), h$ is the sedimentation distance $(\mathrm{m}), t$ is the sedimentation time $(\mathrm{s}), \rho_{s}$ is the density of solid particle $\left(\mathrm{kg} / \mathrm{m}^{3}\right)$. By knowing the density of each minerals $\left(\rho_{s}\right)$ and setting a proper sedimentation height $(h)$, the sedimentation time $(t)$ for obtaining the particles smaller than $-5 \mu \mathrm{m}$ is derived. To conduct the elutriation, $50 \mathrm{~g}$ mineral was distributed into a 10L barrel and stirred to prepare the turbid liquid. Upon the agitation was ceased and the liquid surface was stable, the time counting started. After the required sedimentation time $t$, the liquid above height $h$ was siphoned out, then the barrel was filled with water and the process was repeated until the siphoned liquid was not turbid anymore. The siphoned product was then dried after sedimentation. The $-5 \mu \mathrm{m}$ samples of magnesite, dolomite and quartz were all obtained by this method.

The minerals were stored in a desiccator with nitrogen atmosphere. The results of chemical analysis of the samples are listed in Table 1, which indicated that the purities of magnesite, dolomite and quartz were $98.66 \%, 98.98 \%$ and $99.78 \%$ respectively. Distilled water and analytical grade chemicals such as $\mathrm{HCl}, \mathrm{NaOH}$ and Dodecylamine (DDA) were used in all experiments. 
Table 1. The results of chemical analysis of the single minerals

\begin{tabular}{ccccccc}
\hline Samples & $\mathrm{MgO} / \%$ & $\mathrm{CaO} / \%$ & $\mathrm{SiO}_{2} / \%$ & $\mathrm{Al}_{2} \mathrm{O}_{3} / \%$ & $\mathrm{FeO} / \%$ & $\mathrm{Purity} / \%$ \\
\hline Magnesite & 47.17 & 0.40 & 0.17 & - & - & 98.66 \\
Dolomite & 22.85 & 29.21 & 0.74 & 0.19 & 0.01 & 98.98 \\
Quartz & - & - & 99.78 & - & 0.05 & 99.78 \\
\hline
\end{tabular}

\subsection{Flotation Tests}

Single mineral and artificial minerals flotation tests were carried out in a mechanical agitation flotation machine, the procedure is shown in Fig.1. The impeller speed was fixed at 1800 $\mathrm{r} / \mathrm{min}$. The single mineral flotation test was prepared by adding $3.0 \mathrm{~g}$ of minerals to $30 \mathrm{~mL}$ of solutions. After adding the desired amount of reagents, the froth flotation was continued during which a concentrate was collected. The floated and unfloated particles were collected, filtered and dried. The flotation recovery was calculated based on solid weight distributions between the two products. The $30 \mathrm{~mL}$ mechanical agitation flotation machine was also used in artificial mineral mixture flotation, the size fraction of quartz was $-100+65 \mu \mathrm{m}$ and magnesite (dolomite) was $-5 \mu \mathrm{m}$. For two minerals mixture, $3.0 \mathrm{~g}$ of magnesite (quartz) and proportional quartz (dolomite) were mixed, and for the three minerals mixture of magnesite, dolomite and quartz, $2.7 \mathrm{~g}$ magnesite, $0.3 \mathrm{~g}$ quartz and proportional dolomite were mixed for the flotation tests. Products were filtrated, dried and weighed for assessing the recovery by multi-elemental chemical analysis. The $\mathrm{pH}$ of the mineral suspension was adjusted to a desired value by adding $\mathrm{NaOH}$ or $\mathrm{HCl}$ stock solutions. There was a 2 min conditioning period after the reagent addition. The flotation was conducted for a total of $3 \mathrm{~min}$. The errors of the recovery were found to be within $3.0 \%$ after at least three tests at each condition, and the average values are reported.

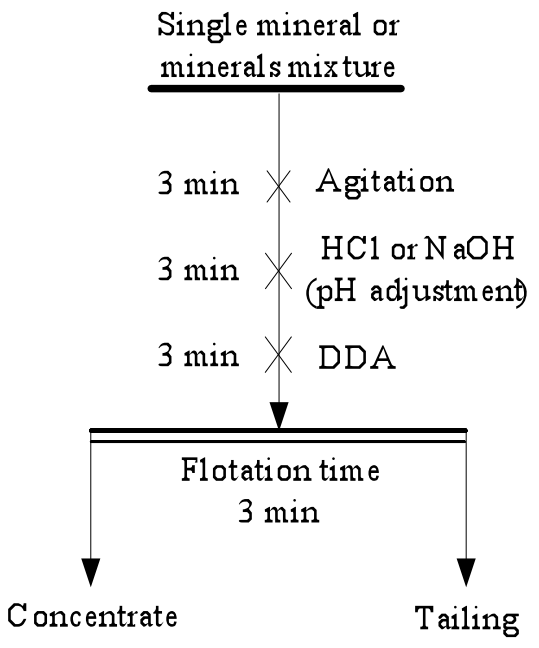

Fig. 1 The procedure of single mineral and artificial minerals flotation tests

\subsection{Zeta-potential Measurements}

In order to measure the zeta-potential of magnesite, dolomite and quartz experiments were carried out using the micro-electrophoresis method. Electrophoretic mobility of dolomite, magnesite and quartz particles were measured with a Nano-ZS90 Micro-Electrophoresis Apparatus. $1.5 \mathrm{~g}$ each of samples for magnesite, dolomite and quartz were conditioned in $100 \mathrm{~mL}$ of distilled water and in DDA acetic solution $\left(8.6 \times 10^{-4} \mathrm{M}\right)$ for $10 \mathrm{~min}$, and the suspension was allowed to stand for another $15 \mathrm{~min}$ to let the larger particles settled. Fine particles in the removing suspension were used in the measurements. Twenty measurements were made for each data point and the averages of these measurements were used to calculate electrokinetic potentials. The $\mathrm{pH}$ of the suspensions was adjusted by $\mathrm{HCl}$ and $\mathrm{NaOH}$. In order to assess the accuracy of zeta-potential measurements, the zeta-potential was measured for at least five independent suspensions. The average values were reported and the measurement errors were found to be 
within $5 \mathrm{mV}$.

\subsection{Contact angle measurements}

Magnesite, dolomite and quartz samples of high purity were used in this study. The high grade lump magnesite, dolomite and quartz ore was cut into slices about $20 \mathrm{~mm}$ long, $10 \mathrm{~mm}$ wide and $3 \mathrm{~mm}$ thick, and they were first embedded using epoxy resin. The embedded specimens were polished using 60, 240, 500 and 1000 grit silicon carbide papers sequentially. The initial polishing was done by using $0.05 \mu \mathrm{m}$ aluminum oxide powder. When passing from one polishing material to the next finer grade, the polished surfaces of the sample was washed with distilled water, to remove any traces of the polishing powder, in all cases. The sessile drop technique was used for contact angle measurements with a JC2000A Contact Angle Goniometer, and accuracy of contact angle is $\left.\pm 1^{\circ}\right)$. The sample disc treated with DDA acetic solution $\left(8.6 \times 10^{-4} \mathrm{M}\right)$ and dried in vacuum was placed in a rectangular glass chamber and a liquid drop was introduced onto the substrate through a micro syringe. Liquid drops were first deposited gently onto the substrates with approximately $4 \mathrm{~mm}$ drop base diameter. The needle connected to the syringe was then partly immersed under the drops for liquid withdrawal. The deflation was achieved when the drop base shrank about $1 \mathrm{~mm}$, then we removed the needle completely to obtain a complete drop shape profile. The captured images was processed and measured to obtain the receding contact angles. The procedure of receding contact angle measurement is illustrated in Fig. 2. The measurements were repeated six times for each condition, and the average value was reported. All measurements were carried out at $25 \pm 2{ }^{\circ} \mathrm{C}$.

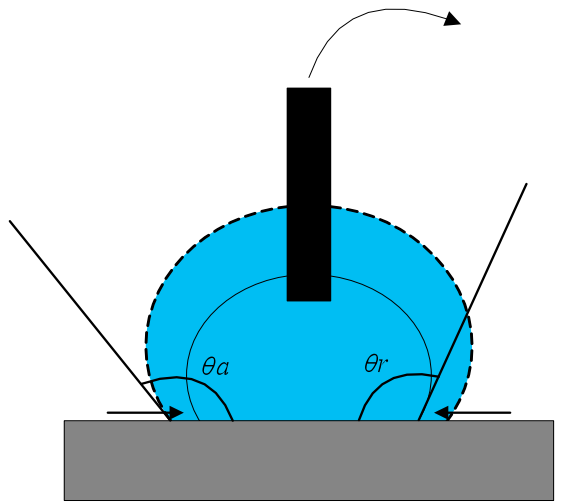

Fig.2 Method of measuring receding contact angle, $\theta_{a}$ indicates advancing contact angle, $\theta_{r}$ indicates receding contact angle

\section{Results and discussion}

\subsection{Microflotation test}

The objective of this study was to investigate the interaction of fine magnesite/dolomite and quartz particles in the flotation process. The single mineral floatability of magnesite, dolomite and quartz with surfactant DDA acetic, and the influence of $\mathrm{pH}$ on their flotation were investigated at first.

The single mineral flotation recovery of magnesite, dolomite and quartz with different DDA acetic dosage are shown in Fig. 3. It can be seen from the figure that the recovery of quartz could reach $96.66 \%$ and dolomite reached $49 \%$ with DDA concentration of $8.6 \times 10^{-4} \mathrm{M}$, but magnesite hardly float under this condition. Fig. 4 shows the flotation recovery of magnesite, dolomite and quartz as a function of $\mathrm{pH}$ with surfactant DDA acetic concentration of $8.6 \times 10^{-4} \mathrm{M}$. It can be seen that floatability of magnesite, dolomite and quartz had small variation within a wide $\mathrm{pH}$ range. 

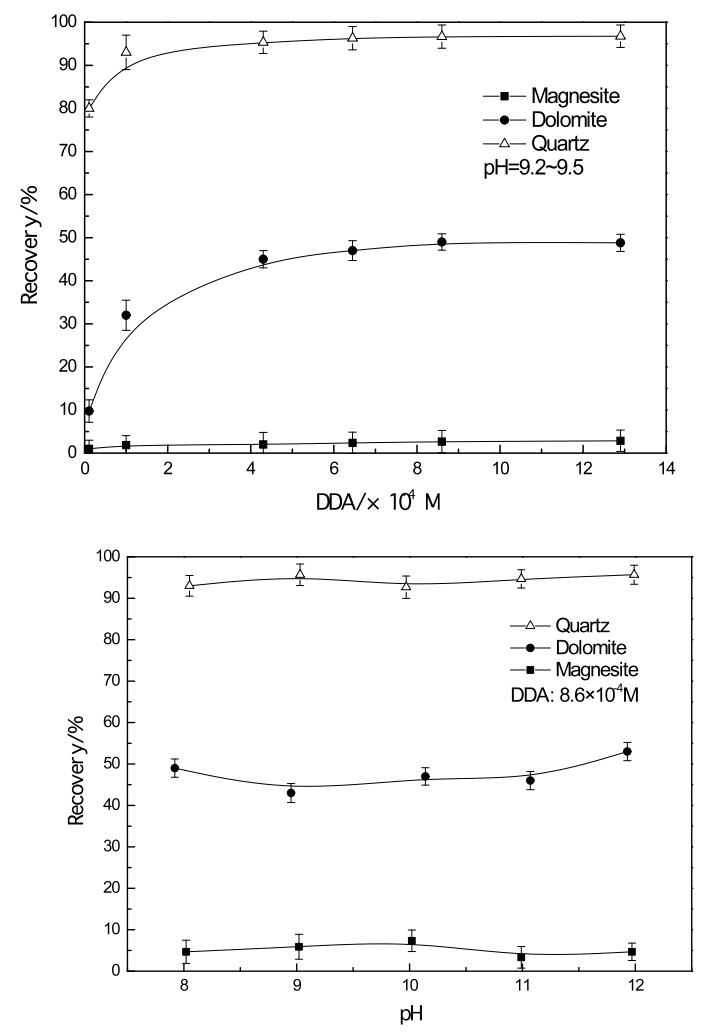

Fig. 3 Relationship between the recovery of minerals and dodecylamine acetate dosage

Fig. 4 Relationship between the recovery of minerals and $\mathrm{pH}$ value

To avoid competitive adsorption, an adequate dosage of DDA $8.6 \times 10^{-4} \mathrm{M}$ was used for the artificial mixture flotation. Fig. 5 shows the flotation recovery of magnesite and quartz in the artificial mixture. It can be seen that the recovery of quartz was reduced dramatically (from $96.66 \%$ to $37.15 \%$ ) when its content was $5 \%$, and as its content increased, the recovery gradually increased. On the other hand, the recovery of magnesite increased with the quartz content increasing. In the presence of fine magnesite particles, a high percentage of coarse quartz particles were not able to be recovered indicating an apparently depressing effect of fine magnesite on quartz.

In the flotation of artificial mixture of fine dolomite and coarse quartz, similar results was presented in Fig. 6. It can be seen that the recovery of quartz reduced with the dolomite content increasing. When the content of fine dolomite increased from $2.5 \%$ to $20 \%$, the recovery of coarse quartz reduced from $91.20 \%$ to $75.08 \%$. On the other hand, the recovery of dolomite increased with the quartz content increasing. Fig. 7 shows the flotation recovery of fine magnesite, fine dolomite and coarse quartz in flotation. It can be seen that the recovery of quartz reduced with the dolomite content increasing, but the recovery of magnesite stayed nearly unchanged. The results told that the particle interaction occurred between dolomite and quartz, but not between dolomite and magnesite. 


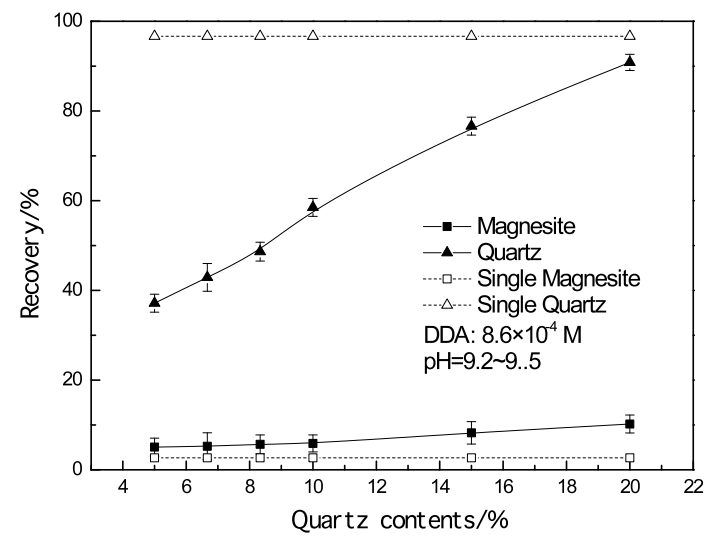

Fig. 5 The recovery of fine magnesite $(-5 \mu \mathrm{m})$

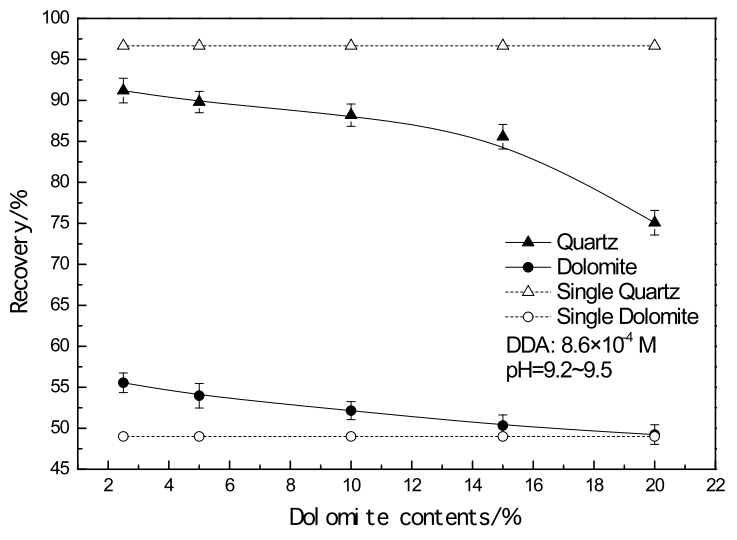

Fig. 6 The recovery of fine dolomite $(-5 \mu \mathrm{m})$ and coarse quartz $(-100+65 \mu \mathrm{m})$ in the flotation and coarse quartz $(-100+65 \mu \mathrm{m})$ in the flotation of their artificial mixture of their artificial mixture

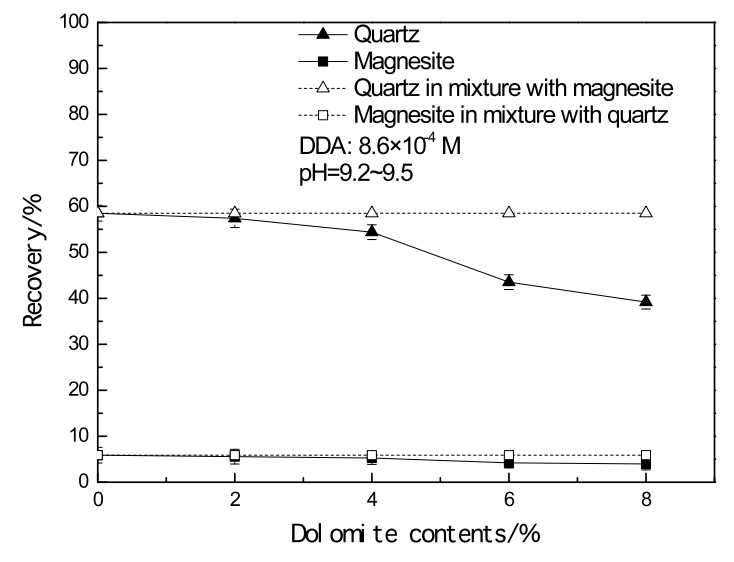

Fig.7 Influence of fine dolomite $(-5 \mu \mathrm{m})$ on the recoveries of fine magnesite $(-5 \mu \mathrm{m})$ and coarse quartz $(-100+65 \mu \mathrm{m})$ in their artificial mixture

It can be concluded from the results above that the recovery of minerals can be influenced in the presence of other fine mineral particles in some condition. However the mechanism could be very complex because it is usually a combination of many causes, which includes the $\mathrm{pH}$ vibration, dissolved ions from mineral surface as well as entrainment effect (Cilek, 2009; Hubbard, 2004; Savassi et al., 1998; Smith and Warren, 1989). However, in this case it can be seen that the floatability of these minerals was insensitive to $\mathrm{pH}$ vibration, besides the recovery of quartz was unusually decreased. The results indicated that fine and coarse particles with different surface properties may interact and thus influenced their individual float behavior. In order to validate this assumption, we calculated the interaction force between magnesite, dolomite and quartz particles based on extended-DLVO theory to evaluate their aggregation/dispersion possiblity. Zeta potential and contact angles are measured to get the parameters for calculation.

\subsection{Zeta-potential analysis}

The zeta potential of magnesite, dolomite and quartz in the absence and presence of DDA is given in Fig. 8 and Fig. 9. Magnesite has zero point of charge (z. p. c) at pH 6.7, dolomite has zero point of charge (z. p. c) at pH 6.0, and quartz has zero point of charge (z. p. c) at pH 2.0. Above the mineral's z. p. c. magnesite, dolomite and quartz surfaces exhibit negative charge and positively charged DDA ions adsorbed on surfaces and due to diminishing of $\mathrm{OH}^{-}$(potential determining) ions, z. p. c. of magnesite, dolomite and quartz were shifted to more alkaline $\mathrm{pH}$ value. Above the z. p. c. , magnesite, dolomite and quartz have negative charge and DDA ions can be adsorbed on minerals surfaces physically by electro-static force and resulting in the increase of positive surface charge of mineral. 


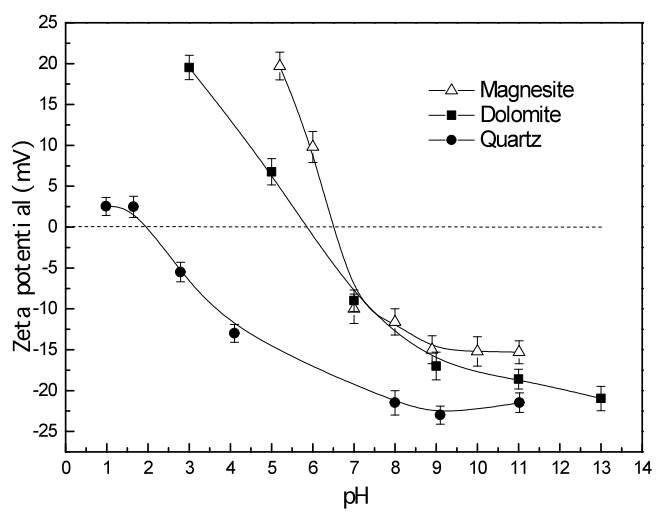

Fig. 8 Zeta potential of magnesite, dolomite and quartz as a function of $\mathrm{pH}$

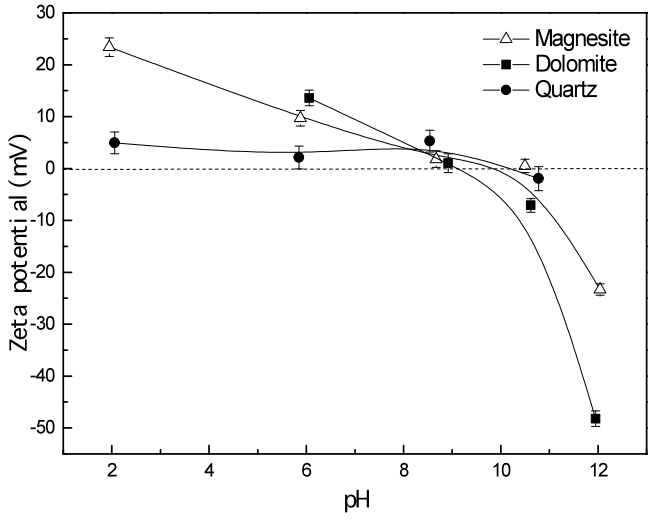

Fig.9 Zeta potential of minerals in DDA solution $\left(8.6 \times 10^{-4} \mathrm{M}\right)$ as a function of $\mathrm{pH}$

\subsection{Wettability and surface tension}

In practice, the conditions under which contact angles are measured are far from ideal to meet the requirements of the Young's equation, which needs the solid surfaces to be chemically homogenous, smooth, flat, non-porous, insoluble, non-deformable and non-reactive quality (Al-Yaseri et al., 2016; LAM et al., 2002; Lam et al., 2001; Lin and Lin, 2003; Shedid and Ghannam, 2004; Tavana et al., 2004). The observed contact angles when the liquid is advancing over a dry surface or receding from a wet surface are taken as the advancing contact angle and receding contact angle, respectively. The differences between these two types of contact angle are noticeable on all rough or dirty surfaces which is referred to as contact angle hysteresis ( $\mathrm{Li}$ et al., 2015). The receding contact angles are often preferred for flotation systems due to its better commitment with flotation response verified in several studies (Alghunaim et al., 2016; Gence, 2006; Kim et al., 2000; Kwok and Neumann, 1999; Lin et al., 2016; Yehia and Al-Wakeel, 2000).

The measured receding contact angle values at the magnesite, dolomite and quartz surfaces in distilled water and glycerin in the absence and presence of surfactant DDA are given in Tab. 2. The contact angle measurements showed that the magnesite, dolomite and quartz minerals have no natural floatability by giving a small contact angle in distilled water. It can be observed from Tab. 1, which surfactant DDA caused an obvious increase in the contact angle at the quartz and dolomite surface, but hardly any increase at the magnesite surface. It can be concluded from the results that the hydrophobicity of quartz surface was improved significantly after treatment with DDA. On the other hand, the hydrophobicity of dolomite was improved slightly in the presence of DDA, and hardly any improvement on magnesite.

Table 2 Average receding contact angle with and without surfactants in deionized water and glycerin $\left(\theta^{\circ}\right)$

\begin{tabular}{ccccccc}
\hline \multirow{2}{*}{ Minerals } & \multicolumn{2}{c}{ Magnesite } & \multicolumn{2}{c}{ Dolomite } & \multicolumn{2}{c}{ Quartz } \\
\cline { 2 - 7 } & DW & DDA & DW & DDA & DW & DDA \\
\hline DW & 1.3 & 1.6 & 22 & 88 & 0 & 136 \\
GC & 62 & 41 & 28 & 104 & 45 & 138 \\
\hline
\end{tabular}

*Note: DW-distilled water; DDA-surfactant dodecylamine acetic; GC-glycerin

According to Van Oss et al.(van Oss and Good, 1989; van Oss, 1990; Van Oss et al., 1988, 1987; van Oss et al., 1987), the contact angle is related with the polar (Lewis acid-base, AB) and apolar (Lifshitz-van der Waals, LW) components of surface energy of solids as well as solid-liquid interfacial energy. They have derived an equation

$$
(1+\cos \theta) \gamma_{L}=2\left(\sqrt{\gamma_{S}^{L W} \gamma_{L}^{L W}}+\sqrt{\gamma_{S}^{+} \gamma_{L}^{-}}+\sqrt{\gamma_{S}^{-} \gamma_{L}^{-}}\right)
$$

Because most oxidized minerals have mono-polar surface, for which, $\gamma_{S}{ }^{+-} \approx 0$, equation (1) can be simplified as

$$
(1+\cos \theta) \gamma_{L}=2\left(\sqrt{\gamma_{S}^{L W} \gamma_{L}^{L W}}+\sqrt{\gamma_{S}^{-} \gamma_{L}^{-}}\right)
$$

Thus, by contact angle $(\theta)$ measurements with only two different liquids (both must be polar) with 
known $\gamma_{L}{ }^{\mathrm{LW}}, \gamma_{L}{ }^{+}, \gamma_{L}{ }^{-}$values, using Eq. (2) twice, the values $\gamma_{S}{ }^{\mathrm{LW}}$ and $\gamma_{S}{ }^{-}$of magnesite, dolomite and quartz can be determined.

Hamaker constant can be determined by $\gamma_{S}{ }^{\mathrm{LW}}$ with the following equation (Bergström, 1997):

$$
A=1.51 \times 10^{-21} \gamma_{s}^{L W}
$$

Tab. 3 shows the known values of the surface energy components of water and glycerin, and the Hamaer constants and values for the components of surface energy of magnesite, dolomite and quartz are calculated on the basis of Eq. (3) and (4) and presented in Tab. 4.

Table 3 the surface tension parameters of water and glycerin

\begin{tabular}{ccccc}
\hline Species & $\gamma_{L}\left(\mathrm{~mJ} / \mathrm{m}^{2}\right)$ & $\gamma_{L}^{d}\left(\mathrm{~mJ} / \mathrm{m}^{2}\right)$ & $\gamma_{L}^{+}\left(\mathrm{mJ} / \mathrm{m}^{2}\right)$ & $\gamma_{L}^{-}\left(\mathrm{mJ} / \mathrm{m}^{2}\right)$ \\
\hline Water & 72.8 & 21.8 & 25.5 & 25.5 \\
Glycerin & 64 & 34 & 3.92 & 57.4 \\
\hline
\end{tabular}

Table 4 the values of components of surface energies and Hamaker constants of magnesite, dolomite and quartz

\begin{tabular}{cccc}
\hline Species & $\mathrm{A}\left(10^{-20} \mathrm{~J}\right)$ & $\gamma_{S}^{d}\left(\mathrm{~mJ} / \mathrm{m}^{2}\right)$ & $\gamma_{S}^{-}\left(\mathrm{mJ} / \mathrm{m}^{2}\right)$ \\
\hline Magnesite & 4.38 & 21.35 & 102.87 \\
Dolomite & 13.75 & 67.07 & 39.91 \\
Quartz & 8.72 & 42.55 & 70.29 \\
\hline
\end{tabular}

\subsection{Calculation of the interaction energy}

The classical DLVO theory is a quantitative theory of the stability to aggregation or dispersions of charged colloidal particles, which was developed and published independently by Derjaguin and Landau in Russia in 1941, and by Verwey and Overbeek in the Netherlands in 1948 (Vincent, 2012).

$$
V_{T D}=V_{W}+V_{E}+V_{H R}+V_{H A}
$$

The classical DLVO theory only considering the electrostatic and van der Waals interaction fails when the surfaces are very hydrophilic or very hydrophobic, for which the contact angle of water is less than $15^{\circ}$ (hydration forces) or greater than $64^{\circ}$ (hydrophobic forces) (Derjaguin and Churaev, 1989). But the hydrophobic aggregation of particles can be well explained in the extended DLVO theory concerning polar interfacial interaction (Hoek and Agarwal, 2006; Hu and Dai, 2003; Ninham, 1999; Ojaniemi et al., 2012; Yoon and Mao, 1996).

In extended DLVO theory, the total interaction energy includes the following components:

(1) Van der Waals interaction, $V_{W}$

(2) Electrical (Coulombic) interactions under constant potential, $V_{E}$

(3) Hydrophobic or hydration interaction, $V_{H}$

$$
V_{T E D}=V_{W}+V_{E}+V_{H}
$$

The magnitude of the above interaction energies is calculated according to the following expressions.

1) Van der Waals interaction, $V_{A}$ (Schenkel and Kitchener, 1960; Verwey and Overbeek, 1955)

$$
V_{W}=-\frac{A_{132}}{6 H} \frac{R_{1} R_{2} f\left(P_{0}\right)}{R_{1}+R_{2}}
$$

Where,

$$
A_{132} \approx\left(\sqrt{A_{11}}-\sqrt{A_{33}}\right)\left(\sqrt{A_{22}}-\sqrt{A_{33}}\right)
$$

for $\mathrm{P}_{0}=2 \pi H / \lambda<0.5$,

$$
f\left(P_{0}\right)=\frac{1}{1+1.77 P_{0}}
$$

for $0.5<\mathrm{P}_{0}<\infty$ 


$$
f\left(P_{0}\right)=-\frac{2.45}{60 P_{0}}+\frac{2.17}{180 P_{0}^{2}}-\frac{0.59}{420 P_{0}^{3}}
$$

Based on equations $(7) \sim(10)$, the Van der Waals interaction energies between magnesite, dolomite and quartz particles are calculated and illustrated in Fig. 10.

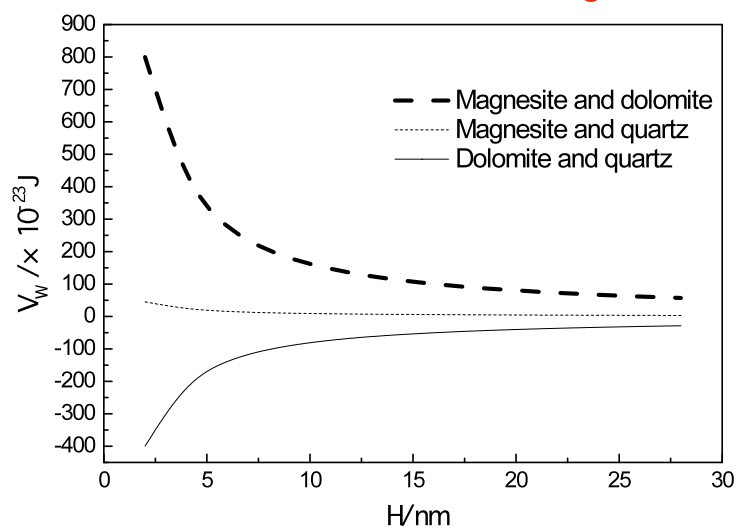

Fig. 10 Van der Waals interaction energy between mineral particles

2) Electrical (Coulombic) interactions under constant potential, $V_{E}$ (Hogg et al., 1966; Pugh and Kitchener, 1971)

$$
V_{E}=\frac{\pi \varepsilon_{0} \varepsilon_{r} R_{1} R_{2}}{R_{1}+R_{2}}\left(\varphi_{1}^{2}+\varphi_{2}^{2}\right)\left[\frac{2 \varphi_{1} \varphi_{2}}{\varphi_{1}^{2}+\varphi_{2}^{2}} p+q\right]
$$

Where

$$
\begin{gathered}
p=\ln \left[\frac{1+\exp (-\kappa H)}{1-\exp (-\kappa H)}\right] \\
q=\ln [1-\exp (-2 \kappa H] \\
\kappa=\left(\frac{2 e^{2} n_{0} z^{2}}{\varepsilon_{0} \varepsilon_{r} k T}\right)^{1 / 2}=\left(\frac{2 e^{2} N_{A} c z^{2}}{\varepsilon_{0} \varepsilon_{r} k T}\right)^{1 / 2}
\end{gathered}
$$

Based on equations (11) (14), the electrical interaction energies are calculated. Fig. 11 and Fig. 12 illustrate the electrical interaction energy between magnesite, dolomite and quartz particles in the absence and presence of DDA $\left(8.6 \times 10^{-4} \mathrm{M}\right)$ at $\mathrm{pH} 9.5$.

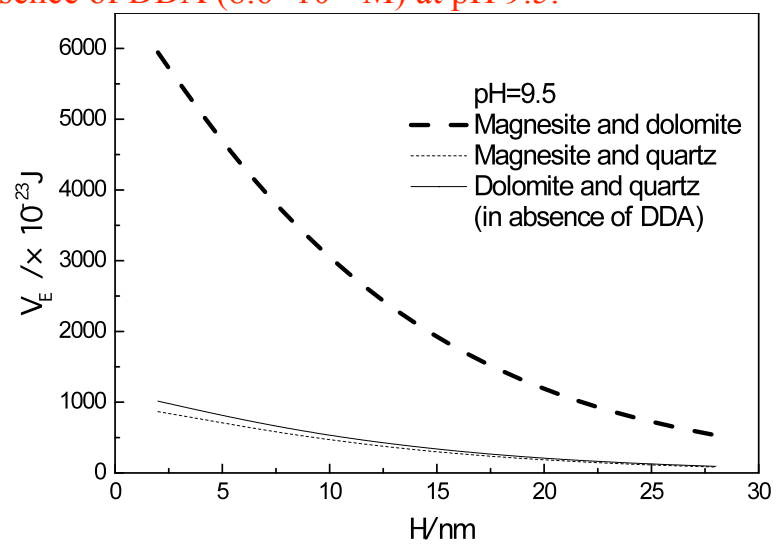

Fig. 11 Electrical interaction energy between mineral particles in absence of DDA 


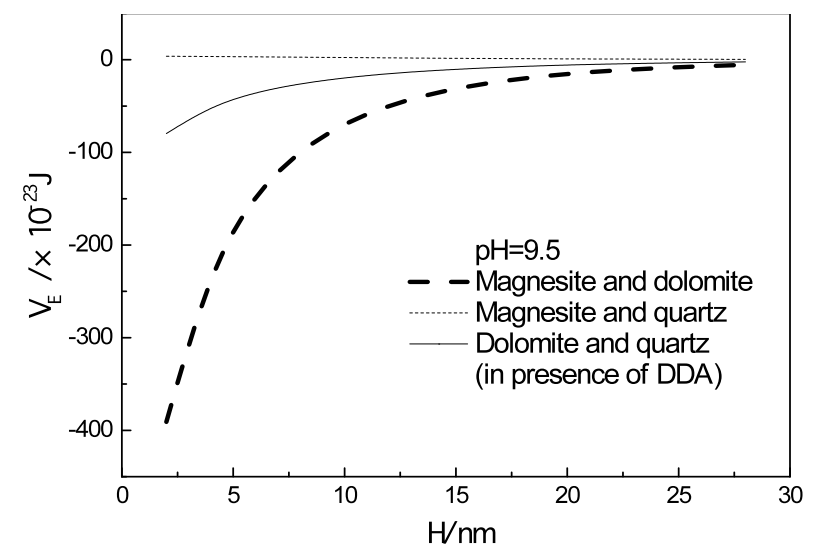

Fig. 12 Electrical interaction energy between mineral particles in presence of DDA

3) Polar interfacial interaction (Claesson et al., 1986; Israelachvili and Pashley, 1982)

$$
V_{H}=2 \pi \frac{R_{1} R_{2}}{R_{1}+R_{2}} h_{0} V_{H}^{0} \exp \left(\frac{H_{0}-H}{h_{0}}\right)
$$

To calculate $V_{H}$ at a distance $H$ the 'decay length' $h_{0}$ has to be known, but its value is still in argument and varies from $0.2 \mathrm{~nm}$ (for non-hydrogen bonded water molecules) (Chan et al., 1979) to as high as $13 \mathrm{~nm}$ (Christenson and Claesson, 1988). However, a reasonable value for $h_{0}$ seems to be about $1 \mathrm{~nm}$ (Van Oss, 2006). $H_{0}$ is the minimum equilibrium contact distance between particles, $H_{0}=0.163 \mathrm{~nm}$ according to Van Oss(van Oss, 1990). The acid-base free energy per unit area between the surfaces can be calculated by the following equation:

$$
V_{H}^{0}=2\left[\sqrt{\gamma_{3}^{+}}\left(\sqrt{\gamma_{1}^{-}}+\sqrt{\gamma_{2}^{-}}-\sqrt{\gamma_{3}^{-}}\right)+\sqrt{\gamma_{3}^{-}}\left(\sqrt{\gamma_{1}^{+}}+\sqrt{\gamma_{2}^{+}}-\sqrt{\gamma_{3}^{+}}\right)-\sqrt{\gamma_{1}^{+} \gamma_{2}^{-}}-\sqrt{\gamma_{1}^{-} \gamma_{2}^{+}}\right]
$$

Based on equations (15) and (16) together with the surface energy parameters in Tab. 4, the polar interfacial interaction energies are calculated. Fig. 13 and Fig. 14 illustrate the polar interfacial interaction energy between magnesite, dolomite and quartz particles in the absence and presence of DDA $\left(8.6 \times 10^{-4} \mathrm{M}\right)$ at $\mathrm{pH}$ 9.5. It can be seen that the strength and distribution of $\mathrm{V}_{\mathrm{W}}$, $V_{E}$ and $V_{H}$ interactions are different from each other, which results in a complex profile of total E-DLVO interaction energy.

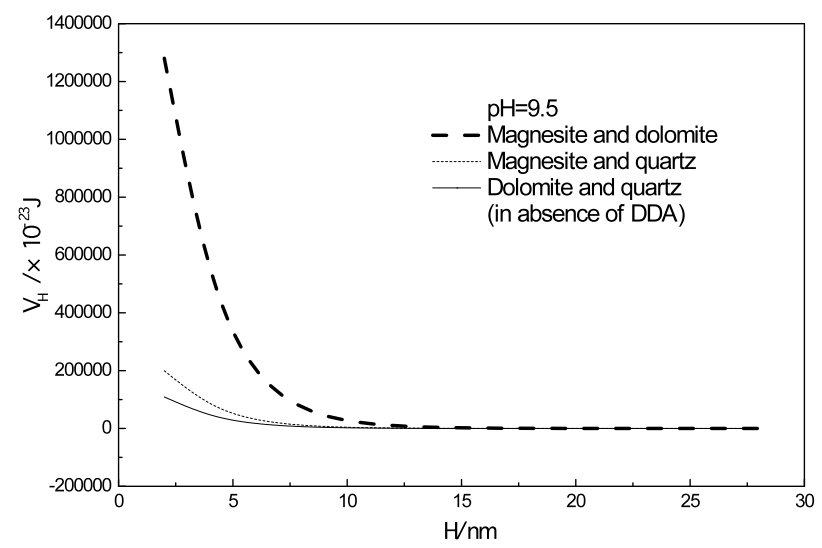

Fig. 13 Polar interfacial interaction energy between mineral particles in absence of DDA 


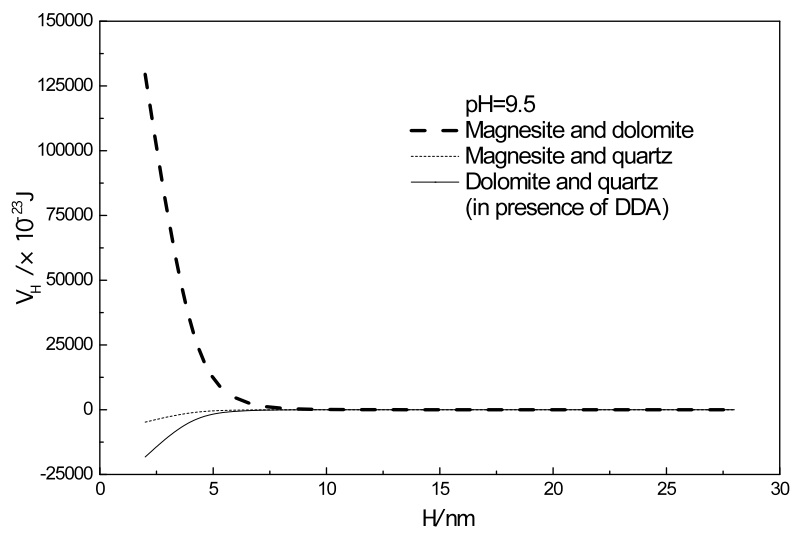

Fig. 14 Polar interfacial interaction energy between mineral particles in presence of DDA

Based on equations (5) (16), the total interaction energies are calculated. Fig. 15 illustrates the interaction energy between magnesite, dolomite and quartz particles at $\mathrm{pH}$ 9.5. DLVO energy profiles indicated that the interaction energy at $\mathrm{pH} 9.5$ in absence and presence of DDA will be almost same. It cannot explain the different interaction behavior in flotation shown in Fig. 5 7. The E-DLVO forces profiles, however, exhibit an evident repulsion between magnesite-quartz and dolomite-quartz particles in absence of DDA and a strong attraction in presence of $8.6 \times 10^{-4} \mathrm{M}$ DDA at pH 9.5 as shown in Fig. 15 (a) and (b), which indicated that hydrophobic aggregation takes place between magnesite and quartz particles, and dolomite and quartz particles adsorbing DDA. These results provide the evidence that E-DLVO theory can explain the interaction behavior between magnesite and quartz, and dolomite and quartz particles in flotation. Similar results have been frequently reported by previous studies, which verified the validity of E-DLVO theory (Tian et al., 2013; Wang et al., 2013; Zhao et al., 2016) . In collector DDA solution, the strong hydrophobic attractive forces (polar interfacial interaction) between magnesite and quartz, dolomite and quartz particles make them tend to aggregate in the pulp, and thus reduced the recovery of quartz. On the other hand, It can be seen in Fig. 15 (c) that the interaction energy between magnesite and dolomite particles are repulsive, which agrees with the experiment results shown in Fig. 7 that magnesite and dolomite had hardly any interaction in flotation. The SEM analysis of the float products of shown in Fig. 16 demonstrating the serious coating of fine magnesite and dolomite particles on quartz surface, which further proved that fine-coarse particle aggregation existed in the flotation, and the prediction done by interaction energy calculation was correct. From the results of flotation test, theoretical calculation and SEM analysis, it is proved that the fine hydrophilic magesite and dolomite particles can depress the float of quartz by aggregating on its surface so to reduce its hydrophobicity and prevent quartz from being collected by air bubble.

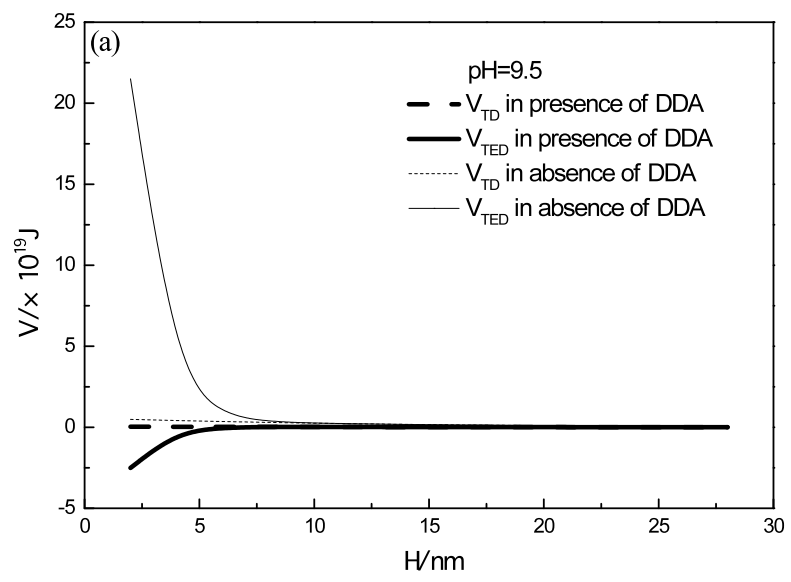



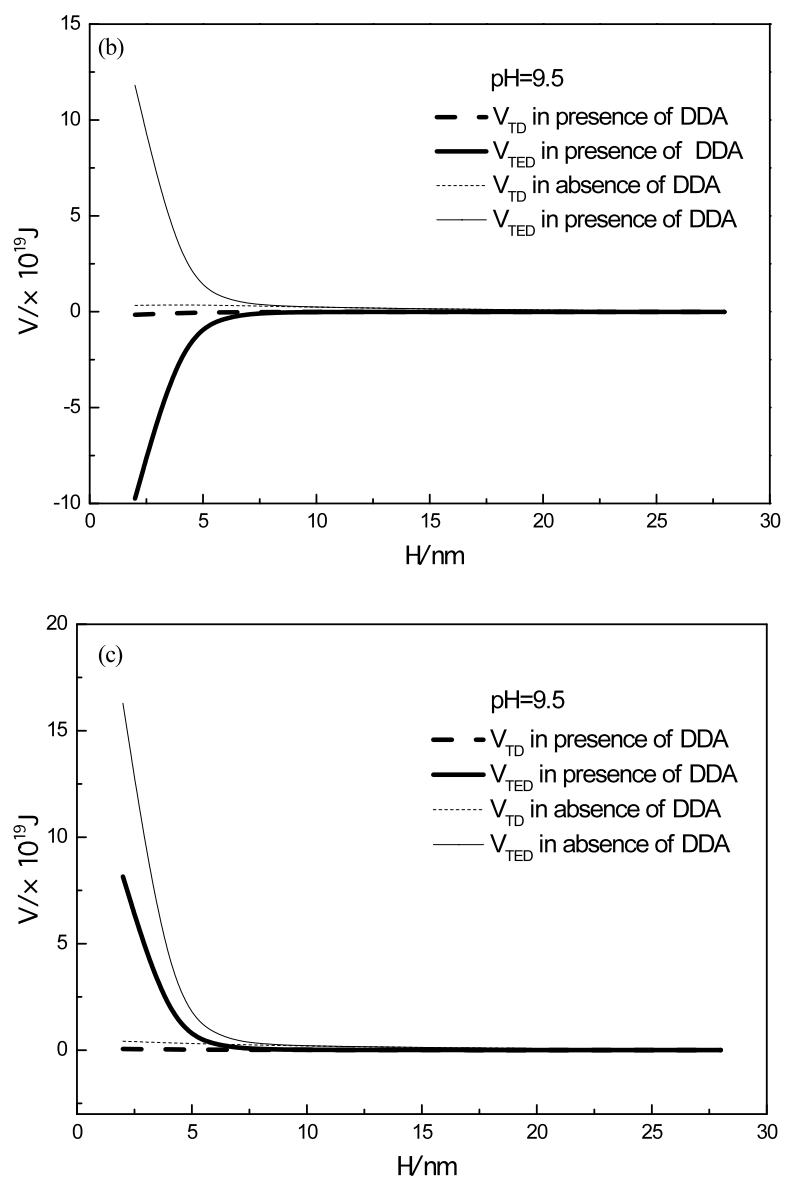

Fig.15 DLVO and the extended DLVO interaction energy profiles for magnesite, dolomite and quartz in DDA solution, (a) magnesite and quartz; (b) dolomite and quartz; (c) magnesite and dolomite.

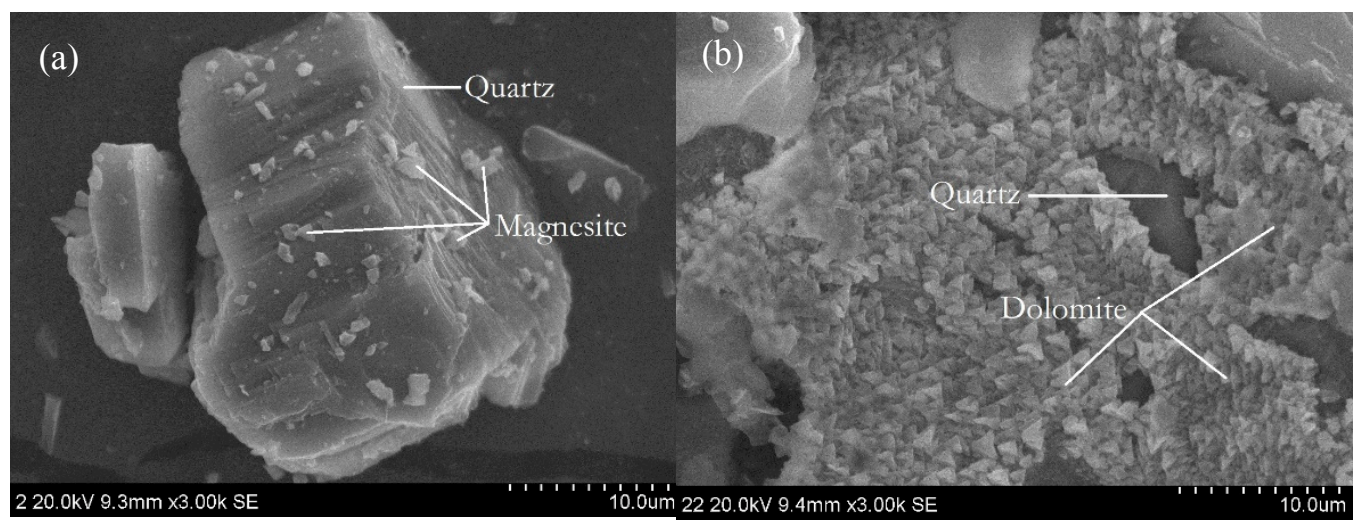

Fig.16 SEM analysis of the float products of quartz-magnesite mixture (a), quartz-dolomite mixture(b) exhibits serious coating of fine magnesite and dolomite particles on quartz

\section{Conclusion}

From the abovementioned, proof for the depressing effect of fine hydrophilic particle on hydrophobic minerals together with the insight for its mechanisms have been provided. Some important original data including zeta-potential, contact angle and surface tension of magnesite, dolomite and quartz were provided in the presence and absence of DDA in this study, which can be referred by further research. 
The experiment results showed that at $\mathrm{pH}=9.2 \sim 9.5$, with DDA dosage of $8.6 \times 10^{-4}$, fine $(-5 \mu \mathrm{m})$ hydrophilic magnesite and dolomite particles depressed the flotation of coarse $(-100+65 \mu \mathrm{m})$ quartz particles. The recovery of quartz was reduced dramatically from $96.66 \%$ to $37.15 \%$ when the content of quartz was $5 \%$ in the flotation with fine magnesite. And when the content of fine dolomite was increased from $2.5 \%$ to $20 \%$, the recovery of coarse quartz was reduced from $91.20 \%$ to $75.08 \%$. The discovered phenomenon is novel in magnesite flotation that fine magesite and dolomite particles can depress the float of quartz and thus influence the reverse flotation separation of magnesite. In the past, the influence of particles size (Bravo et al., 2005) and particles interaction on flotation was related in many ways including particles aggregation, flocculation, entrainment and "piggy-backing" etc. (Liu et al., 2015; $\mathrm{Ng}$ et al., 2015; Wang et al., 2015), but clearly depressing effect from one mineral to another was rarely mentioned, yet significant for the flotation as demonstrated above. It can be implied that the coating of fine hydrophilic particles on the surface of hydrophobic minerals can prevent it from being collecting by air bubble and leads to an apparently depressing effect.

In addition to the traditional recognition that the recovery of minerals are determined by adsorption of collectors on minerals, the interacting effect between mineral particles should be paid attention. The depressing effect by fine hydrophilic mineral particles suggests effective dispersing methods to be invented to diminish the coating for more effective flotation in future research. It is interesting to note that the interfacial interaction energy determining the aggregating behavior was theoretically calculated and analyzed, having good agreements with the experimental results. Considering the components of interaction energy, some clues to dispersing measurements can be derived, including modification of surface potential, wettability and surface tension by controlling $\mathrm{pH}$ or adding dispersants, however the measure should be investigated case by case.

\section{Acknowledgements}

The authors would like to acknowledge the financial support from the National Science Foundation of China (No. 51374079, No 51504053), and the China Postdoctoral Science Foundation (No. 2015M571324), the Ph.D start up foundation of Science and Technology Department of Liaoning Province (20151157), and the foundation of Education Department of Liaoning Province (L20150180).

\section{References:}

Alghunaim, A., Kirdponpattara, S., Newby, B.Z., 2016. Techniques for determining contact angle and wettability of powders. Powder Technol. 287, 201-215. doi:10.1016/j.powtec.2015.10.002

Al-Yaseri, A.Z., Lebedev, M., Barifcani, A., Iglauer, S., 2016. Receding and advancing $(\mathrm{CO} 2+$ brine+quartz) contact angles as a function of pressure, temperature, surface roughness, salt type and salinity. J. Chem. Thermodyn. 93, 416-423. doi:10.1016/j.jct.2015.07.031

Anastassakis, G.N., 1999. A study on the separation of magnesite fines by magnetic carrier methods. Colloids Surfaces A Physicochem. Eng. Asp. 149, 585-593.

doi:10.1016/S0927-7757(98)00562-7

Bergström, L., 1997. Hamaker constants of inorganic materials. Adv. Colloid Interface Sci. 70, 125-169. doi:10.1016/S0001-8686(97)00003-1

Botero, A.E.C., Torem, M.L., de Mesquita, L.M.S., 2008. Surface chemistry fundamentals of 
biosorption of Rhodococcus opacus and its effect in calcite and magnesite flotation. Miner. Eng. 21, 83-92. doi:10.1016/j.mineng.2007.08.019

Bravo, S.V.C., Torem, M.L., Monte, M.B.M., Dutra, A.J.B., Tondo, L.A., 2005. The influence of particle size and collector on the flotation of a very low grade auriferous ore. Miner. Eng. 18, 459-461. doi:10.1016/j.mineng.2004.08.006

Chan, D.Y.., Mitchell, D.., Ninham, B.., Pailthorpe, B.., 1979. Dispersion interactions across binary liquid mixtures. A proper account of structural effects. J. Colloid Interface Sci. 68, 462-470. doi:10.1016/0021-9797(79)90303-5

Chen, G., Tao, D., 2004. Effect of solution chemistry on flotability of magnesite and dolomite. Int. J. Miner. Process. 74, 343-357. doi:10.1016/j.minpro.2004.04.004

Christenson, H.K., Claesson, P.M., 1988. Cavitation and the Interaction Between Macroscopic Hydrophobic Surfaces. Science (80-. ). 239, 390-392. doi:10.1126/science.239.4838.390

Cilek, E.C., 2009. The effect of hydrodynamic conditions on true flotation and entrainment in flotation of a complex sulphide ore. Int. J. Miner. Process. 90, 35-44. doi:10.1016/j.minpro.2008.10.002

Claesson, P.M., Blom, C.E., Herder, P.C., Ninham, B.W., 1986. Interactions between water-stable hydrophobic Langmuir-Blodgett monolayers on mica. J. Colloid Interface Sci. 114, 234-242. doi:10.1016/0021-9797(86)90257-2

Derjaguin, B.V., Churaev, N.V., 1989. The current state of the theory of long-range surface forces. Colloids and Surfaces 41, 223-237. doi:10.1016/0166-6622(89)80054-X

Duzyol, S., Ozkan, A., 2011. Correlation of Flocculation and Agglomeration of Dolomite with its Wettability. Sep. Sci. Technol. 46, 876-881. doi:10.1080/01496395.2010.527895

Duzyol, S., Ozkan, A., 2010. Role of hydrophobicity and surface tension on shear flocculation and oil agglomeration of magnesite. Sep. Purif. Technol. 72, 7-12. doi:10.1016/j.seppur.2009.12.011

Gence, N., 2006. Wetting behavior of magnesite and dolomite surfaces. Appl. Surf. Sci. 252, 3744-3750. doi:10.1016/j.apsusc.2005.05.053

Gence, N., Özdağ, H., 1995. Surface properties of magnesite and surfactant adsorption mechanism. Int. J. Miner. Process. 43, 37-47. doi:10.1016/0301-7516(94)00047-4

Hoek, E.M. V, Agarwal, G.K., 2006. Extended DLVO interactions between spherical particles and rough surfaces. J. Colloid Interface Sci. 298, 50-8. doi:10.1016/j.jcis.2005.12.031

Hogg, R., Healy, T.W., Fuerstenau, D.W., 1966. Mutual coagulation of colloidal dispersions. Trans. Faraday Soc. 62, 1638. doi:10.1039/tf9666201638

Hu, Y., Dai, J., 2003. Hydrophobic aggregation of alumina in surfactant solution. Miner. Eng. 16, 1167-1172. doi:10.1016/j.mineng.2003.07.018

Hubbard, A., 2004. Colloidal Science of Flotation. J. Colloid Interface Sci. 273, 343. doi:10.1016/j.jcis.2004.02.003

Israelachvili, J., Pashley, R., 1982. The hydrophobic interaction is long range, decaying exponentially with distance. Nature. doi:10.1038/300341a0

Karaoglu, H., Yanmis, D., Gurkok, S., 2016. Magnesite Enrichment with Pseudomonas oryzihabitans Isolated from Magnesite Ore. Geomicrobiol. J. 33, 46-51. doi:10.1080/01490451.2015.1037938 
Kim, J.S., Friend, R.H., Cacialli, F., 2000. Surface wetting properties of treated indium tin oxide anodes for polymer light-emitting diodes. Synth. Met. 111-112, 369-372. doi:10.1016/S0379-6779(99)00329-X

Kwok, D.Y., Neumann, A.W., 1999. Contact angle measurement and contact angle interpretation. Adv. Colloid Interface Sci. 81, 167-249. doi:10.1016/S0001-8686(98)00087-6

LAM, C., WU, R., LI, D., HAIR, M., NEUMANN, A., 2002. Study of the advancing and receding contact angles: liquid sorption as a cause of contact angle hysteresis. Adv. Colloid Interface Sci. 96, 169-191. doi:10.1016/S0001-8686(01)00080-X

Lam, C.N.C., Ko, R.H.Y., Yu, L.M.Y., Ng, A., Li, D., Hair, M.L., Neumann, A.W., 2001. Dynamic Cycling Contact Angle Measurements: Study of Advancing and Receding Contact Angles. J. Colloid Interface Sci. 243, 208-218. doi:10.1006/jcis.2001.7840

Lange, a. G., Skinner, W.M., Smart, R.S.C., 1997. Fine: Coarse particle interactions and aggregation in sphalerite flotation. Miner. Eng. 10, 681-693. doi:10.1016/S0892-6875(97)00048-4

Li, Y.-F., Wu, C.-J., Sheng, Y.-J., Tsao, H.-K., 2015. Facile manipulation of receding contact angles of a substrate by roughening and fluorination. Appl. Surf. Sci. 355, 127-132. doi:10.1016/j.apsusc.2015.07.078

Lin, C.-T., Lin, K.-L., 2003. Contact angle of $63 \mathrm{Sn}-37 \mathrm{~Pb}$ and $\mathrm{Pb}$-free solder on Cu plating. Appl. Surf. Sci. 214, 243-258. doi:10.1016/S0169-4332(03)00342-8

Lin, T.-S., Zeng, Y.-H., Tsay, R.-Y., Lin, S.-Y., 2016. Deflation rate dependence of receding contact angle on polymeric surfaces. J. Taiwan Inst. Chem. Eng. doi:10.1016/j.jtice.2015.12.008

Liu, J., Wang, X., Lin, C.-L., Miller, J.D., 2015. Significance of particle aggregation in the reverse flotation of kaolinite from bauxite ore. Miner. Eng. 78, 58-65. doi:10.1016/j.mineng.2015.04.009

Lu, S., Song, S., 1991. Hydrophobic interaction in flocculation and flotation 1. Hydrophobic flocculation of fine mineral particles in aqueous solution. Colloids and Surfaces 57, 49-60. doi:10.1016/0166-6622(91)80179-R

Ng, W.S., Sonsie, R., Forbes, E., Franks, G. V., 2015. Flocculation/flotation of hematite fines with anionic temperature-responsive polymer acting as a selective flocculant and collector. Miner. Eng. 77, 64-71. doi:10.1016/j.mineng.2015.02.013

Ninham, B.W., 1999. On progress in forces since the DLVO theory. Adv. Colloid Interface Sci. 83, 1-17. doi:10.1016/S0001-8686(99)00008-1

Ojaniemi, U., Riihimäki, M., Manninen, M., Pättikangas, T., 2012. Wall function model for particulate fouling applying XDLVO theory. Chem. Eng. Sci. 84, 57-69. doi:10.1016/j.ces.2012.08.004

Ozkan, A., Duzyol, S., 2014. Gamma processes of shear flocculation, oil agglomeration and liquid-liquid extraction. Sep. Purif. Technol. 132, 446-451. doi:10.1016/j.seppur.2014.06.001

Ozkan, A., Duzyol, S., 2010. Critical solution surface tension for liquid-liquid extraction. Sep. Purif. Technol. 76, 79-83. doi:10.1016/j.seppur.2010.09.025

Ozkan, S.., 2002. Beneficiation of magnesite slimes with ultrasonic treatment. Miner. Eng. 15, 99-101. doi:10.1016/S0892-6875(01)00205-9

Pugh, R.., Kitchener, J.., 1971. Theory of selective coagulation in mixed colloidal suspensions. J. 
Colloid Interface Sci. 35, 656-664. doi:10.1016/0021-9797(71)90225-6

Santana, A.N., Peres, A.E.C., 2001. Reverse magnesite flotation. Miner. Eng. 14, 107-111. doi:10.1016/S0892-6875(00)00164-3

Savassi, O.N., Alexander, D.J., Franzidis, J.P., Manlapig, E.V., 1998. An empirical model for entrainment in industrial flotation plants. Miner. Eng. 11, 243-256. doi:10.1016/S0892-6875(98)00003-X

Schenkel, J.H., Kitchener, J.A., 1960. A test of the Derjaguin-Verwey-Overbeek theory with a colloidal suspension. Trans. Faraday Soc. 56, 161. doi:10.1039/tf9605600161

Shedid, S.A., Ghannam, M.T., 2004. Factors affecting contact-angle measurement of reservoir rocks. J. Pet. Sci. Eng. 44, 193-203. doi:10.1016/j.petrol.2004.04.002

Smith, P.G., Warren, L.J., 1989. Entrainment of Particles into Flotation Froths. Miner. Process. Extr. Metall. Rev. 5, 123-145. doi:10.1080/08827508908952647

Tavana, H., Lam, C.N.C., Grundke, K., Friedel, P., Kwok, D.Y., Hair, M.L., Neumann, A.W., 2004. Contact angle measurements with liquids consisting of bulky molecules. J. Colloid Interface Sci. 279, 493-502. doi:10.1016/j.jcis.2004.06.090

Tian, Y., Li, Z., Ding, Y., Lu, Y., 2013. Identification of the change in fouling potential of soluble microbial products (SMP) in membrane bioreactor coupled with worm reactor. Water Res. 47, 2015-24. doi:10.1016/j.watres.2013.01.026

Van Oss, C.J., 2006. Interfacial Forces in Aqueous Media (2nd ed.). Marcel Dekker, New York.

van Oss, C.J., 1990. DLVO and Non-DLVO Interactions in Hectorite. Clays Clay Miner. 38, 151-159. doi:10.1346/CCMN.1990.0380206

Van Oss, C.J., Chaudhury, M.K., Good, R.J., 1988. Interfacial Lifshitz-van der Waals and polar interactions in macroscopic systems. Chem. Rev. 88, 927-941. doi:10.1021/cr00088a006

van Oss, C.J., Chaudhury, M.K., Good, R.J., 1987. Monopolar surfaces. Adv. Colloid Interface Sci. 28, 35-64. doi:10.1016/0001-8686(87)80008-8

van Oss, C.J., Good, R.J., 1989. Surface Tension and the Solubility of Polymers and Biopolymers: The Role of Polar and Apolar Interfacial Free Energies. J. Macromol. Sci. Part A - Chem. 26, 1183-1203. doi:10.1080/00222338908052041

Van Oss, C.J., Good, R.J., Chaudhury, M.K., 1987. Determination of the Hydrophobia Interaction Energy-Application to Separation Processes. Sep. Sci. Technol. 22, 1-24. doi:10.1080/01496398708056155

Verwey, E.J.., Overbeek, J.T.., 1955. Theory of the stability of lyophobic colloids. J. Colloid Sci. 10, 224-225. doi:10.1016/0095-8522(55)90030-1

Vincent, B., 2012. Early (pre-DLVO) studies of particle aggregation. Adv. Colloid Interface Sci. 170, 56-67. doi:10.1016/j.cis.2011.12.003

Wang, L., Peng, Y., Runge, K., Bradshaw, D., 2015. A review of entrainment: Mechanisms, contributing factors and modelling in flotation. Miner. Eng. 70, 77-91. doi:10.1016/j.mineng.2014.09.003

Wang, Q., Wang, Z., Zhu, C., Mei, X., Wu, Z., 2013. Assessment of SMP fouling by 
foulant-membrane interaction energy analysis. J. Memb. Sci. 446, 154-163.

doi:10.1016/j.memsci.2013.06.011

Yehia, A., Al-Wakeel, M.I., 2000. Talc separation from talc-carbonate ore to be suitable for different industrial applications. Miner. Eng. 13, 111-116. doi:10.1016/S0892-6875(99)00154-5

Yoon, R.-H., Mao, L., 1996. Application of Extended DLVO Theory, IV: Derivation of Flotation Rate Equation from First Principles. J. Colloid Interface Sci. 181, 613-626. doi:10.1006/jcis.1996.0419

Zhao, L., Zhang, M., He, Y., Chen, J., Hong, H., Liao, B.-Q., Lin, H., 2016. A new method for modeling rough membrane surface and calculation of interfacial interactions. Bioresour. Technol. 200, 451-7. doi:10.1016/j.biortech.2015.10.055 